\title{
Using the product environmental footprint for supply chain management: lessons learned from a case study on pork
}

\author{
Lasse Six ${ }^{1} \cdot$ Bruno De Wilde $^{1} \cdot$ Frederic Vermeiren $^{2} \cdot$ Steven Van Hemelryck $^{2}$ • \\ Mieke Vercaeren ${ }^{2} \cdot$ Alessandra Zamagni $^{3} \cdot$ Paolo Masoni $^{4} \cdot$ Jo Dewulf $^{5}$. \\ Steven De Meester ${ }^{6}$
}

Received: 1 December 2015 / Accepted: 8 December 2016 /Published online: 22 January 2017

(C) The Author(s) 2017. This article is published with open access at Springerlink.com

\begin{abstract}
Purpose The purpose of this study was to test the chainorganization environmental footprint (chain-OEF) approach by applying it to part of a pork production chain in Belgium. The approach is supposed to provide insight into the environmental impact of a specific production chain in an efficient manner by applying pragmatic data collection throughout the chain. This is achieved by allocating the environmental impact of each of the production sites to the product of interest using straightforward allocation rules.

Methods The cradle-to-gate (up to retail) environmental impact of pork was determined by life cycle assessment (LCA), in line with the product and organisation environmental footprint guidelines (PEF and OEF; European Commission 2013b). Foreground data was gathered at a feed production site, two farmers, a slaughterhouse and a meat processing site. All foreground operations are part of the same pork
\end{abstract}

Responsible editor: Adriana Del Borghi

Lasse Six

lasse.six@ ows.be

OWS, Dok Noord 5, 9000 Ghent, Belgium

2 Colruyt Group, Edingsesteenweg 196, 1500 Halle, Belgium

3 Ecoinnovazione, Via Guido Rossa 26, 35020 Padova, Ponte San Nicolò, Italy

4 ENEA, via Martiri di Monte Sole 4, 40129 Bologna, Italy

5 Department of environmental organic chemistry and technology, Ghent University, Coupure Links 653, 9000 Ghent, Belgium

6 Department of industrial biological sciences, Ghent University Campus Kortrijk, Graaf Karel de Goedelaan 5,

8500 Kortrijk, Belgium production chain in Belgium. The chain was completed using background data from Ecoinvent v3.01 (Wernet et al. 2016), Agri-Footprint v1.0 (Blonk 2014), European Life Cycle Database v3.0, LCA Food Database (Nielsen et al. 2003) and OEF Sector Rules Retail (Humbert et al. 2015b). The impact was quantified using the international reference life cycle data system (ILCD) midpoint method for 14 impact categories, but focussing on climate change.

Results and discussion The total carbon footprint of the cradle-to-gate pork production system equals $0.46 \mathrm{~kg}$ $\mathrm{CO}_{2}$-eq. $(100 \mathrm{~g} \text { pork })^{-1}$. This result is quite similar to that of earlier studies analysing the pork production chain: 0.58 and $0.57 \mathrm{~kg} \mathrm{CO}_{2}$-eq. (100 g pork) ${ }^{-1}$ (Bracquené et al. 2011, Agri-Footprint 2014). Most of the carbon footprint was caused by feed production and more specifically, by the feed ingredients and their transport. Grains, soy and palm oil have the largest impact contributions. The farms are responsible for most of the remaining impact. $\mathrm{N}_{2} \mathrm{O}$ and $\mathrm{CH}_{4}$ emissions are the largest cause of greenhouse gas emissions at the farms. Also, in the other 13 considered impact categories, feed production and farming are responsible for more than half of the total impact, mostly followed by meat processing.

Conclusions Applying the chain-OEF approach in this study has shown that a chain LCA can be performed successfully and pragmatic data collection allows obtaining LCA results relatively fast, especially for small or medium-sized enterprises (SMEs). Whereas data availability was not such an issue, the main bottlenecks identified are data management and the link of LCA to other disciplines such as engineering, policy, etc. which could increase the added value of LCA studies.

Keywords Chain-OEF · Pork · Product environmental footprint $\cdot$ Supply chain management 


$\begin{array}{ll}\text { Abbreviations } \\ \text { CV } & \text { Coefficient of variation } \\ \text { DQR } & \text { Data quality rating } \\ \text { HFCs } & \text { Hydrofluorocarbons } \\ \text { ILCD } & \text { International reference life cycle data system } \\ \text { LCA } & \text { Life cycle assessment } \\ \text { LCI } & \text { Life cycle inventory } \\ \text { NACE } & \text { Nomenclature statistique des Activités } \\ & \text { économiques dans la Communauté Européenne } \\ \text { OEF } & \text { Organisation environmental footprint } \\ \text { PM } & \text { Particulate matter } \\ \text { PEF } & \text { Product environmental footprint } \\ \text { SME } & \text { Small or medium-sized enterprise } \\ \text { WWTP } & \text { Wastewater treatment plant }\end{array}$

\section{Introduction}

With a growing world population, the demand for a sustainable food supply is increasing (Ilbery and Maye, 2005). It is therefore essential to be able to analyse and benchmark the environmental sustainability of different food products. To do so, life cycle assessment (LCA) is recommended as the most appropriate method (Finnveden and Moberg, 2005, Guinée et al. 2011). However, LCA as defined by ISO 14040/44 is only a framework leaving many methodological choices open. This results in differentiation of results for similar products, causes confusion and eases greenwashing.

To improve harmonisation and consistency of environmental claims, the European Commission created the Single Market for Green Products Initiative with rules for a product environmental footprint (PEF) and organisation environmental footprint (OEF; European Commission, 2013a, b, c; Galatola and Pant 2014). Apart from these general rules, more stringent standards are defined per product category or per sector during a pilot phase. The initiative aims at lowering the remaining confusion among consumers (TNS Opinion and Social 2014) and to aid producers making reliable green claims. It opens the door for more large-scale application of LCA in industry, e.g. for communication or comparisons, and the new standards are thus welcomed.

Nevertheless, a major constraint of the strict PEF and OEF rules is that the LCA procedure is very much generalized in this initiative and 'typical' processes and organisations are used to model the background data instead of investigating the actual situation and choosing the most appropriate model. Often, these typical processes are modelled using generic data and as such, substitute more specific data from the studied product life cycle (Finkbeiner 2014; Lehmann et al. 2015). This is in contrast to the supply chain feature of LCA which should be aimed at optimizing specific processes and supply chain choices. One of the main positive properties of LCA is the detailed analysis of and interaction with specific suppliers, and stimulation of green procurement and life cycle thinking resulting in innovative business models and positive feedback loops. Although the PEF/OEF initiative may also aim for supply chain optimisation, it seems to put most attention on the sector specific harmonisation, which causes cross sectoral issues such as data management and positive supply chain interaction to receive less attention.

The aim of this paper is to address the above-mentioned concerns and test the practical applicability of the PEF and OEF guidelines in a case study with value chain interactions: the pork supply chain of the Colruyt Group, a large Belgian retailer. Pork production was selected for the following reasons: meat production is an important source of global greenhouse gas emissions (FAO 2014) and plays an important role in the impact associated with retail products (Humbert 2015a), pork is an important contributor to global environmental impacts (Carlsson-Kanyama 1998), it represents an important share of the product portfolio of retailers (De Schryver et al. 2012) and is, by far, the most produced type of meat in Belgium, a net exporter of the product (VLAM 2014). Furthermore, it is also an important in-house product of the Colruyt Group and was previously analysed in an OEF screening study (Quantis 2015). For these reasons, it is interesting to analyse the chain in depth to be able to improve its environmental performance and manage sustainability issues in the supply chain.

\section{Methods}

\subsection{Chain-OEF approach}

The chain-OEF initiative was started to support the PEF/OEF harmonisation effort. It is complementary to the OEF retail pilot and is aimed at testing alternative approaches in the EU pilot testing phase (2013-2017). The two main ingredients of the chain-OEF initiative are linking actors in the supply chain and collecting primary data in a pragmatic way (Fig. 1).

The linking throughout the supply chain is done in order to limit the use of generic market data as much as possible (Pedrazzini et al. 2014) so that suppliers or entire production chains can be differentiated from one another. This allows the selection of the most environment-friendly supply chain or the identification of the most important improvement potentials. Furthermore, the linking of actors is intended to initiate and strengthen communication and collaboration throughout the supply chain in order to allow the effective reduction of the most important environmental impacts.

Pragmatic data collection in this context differs from more detailed, individual unit operation-focussed LCA data collection by treating combined unit operations (i.e. entire processing plants) as black box models, without internal details but with known in- and outputs (e.g. based on accounting balances), 


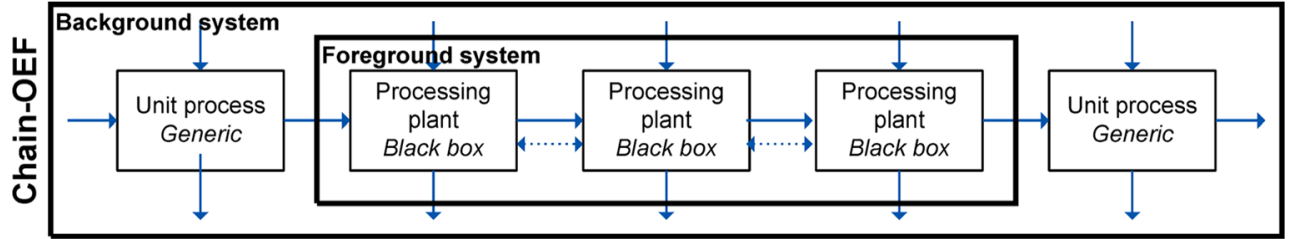

Fig. 1 Chain-OEF approach (background system data is derived from databases or literature and is generally based on sector averages; foreground system data is gathered on-site; solid arrows indicate material

instead of going into detail and investigating all the processes and internal exchanges that form the large units. As such, the ease and efficiency of data collection are improved allowing the relatively rough assessment of supply chains with similar effort as detailed assessments of single supply chain actors. This pragmatic data collection is not novel as such; similar approaches have been applied successfully in other LCA studies, evaluating e.g. average product impacts, which concluded that the obtained results are in line with those of earlier research (Dalgaard et al. 2007; Djekic et al. 2015; Winkler et al. 2016). It is, however, an important feature of chain-OEF as it reduces the assessment cost for each of the chain actors, which is crucial for adoption beyond the testing phase.

This paper assesses the real life application of the chainOEF approach for detailed supply chain analysis with the aim of identifying major environmental hotspots and improvement potentials and specifically addresses the following two challenges.

First of all, the level of data gathering is an important aspect to be studied. To convince all actors to join an LCA of their complete supply chain, resources (costs and time) should be minimized while an acceptable balance between accuracy and data availability should be achieved. Most companies and organizations dispose of data and information at an organizational level (annual environmental reports, balances, etc.). Environment-related data are much less readily available at the product level. Therefore, the data availability at different levels of a company must be taken into account. It is also interesting to analyse the allocation method for these different levels of data to products and choosing a functional unit that allows a certain grouping of products within one functional unit in such a way that not each and every product requires a separate LCA study.

Secondly, the supply chain actors need to be brought together and must discuss how they perceive an LCA study and how steps towards collaboration and improvement can be taken.

\subsection{Goal}

On the one hand, the goal of this case study is to calculate the specific PEF of pork produced within the supply chain of one of the largest Belgian retailers, Colruyt Laagste Prijzen (Colruyt Lowest Prices), so as to identify environmental and energy flows; dotted arrows indicate interactions on sustainability within the supply chain)

hotspots and to define strategies for the optimisation of the pork supply chain.

On the other hand, the study is also intended as a test of pragmatic data collection throughout the supply chain and testing possible supply chain interactions (chain-OEF), using primary, high-quality data from several actors within the production chain: an animal feed production facility, two pig farms, a slaughterhouse and a meat processing site, supplemented downstream with literature models for a local distribution centre and retail stores.

\subsection{Scope}

In line with the declared goal and the chain-OEF approach, the scope is limited to one specific cradle-to-gate production system of pork. This limitation of the scope is allowed by the PEF guide as long as it is appropriate for the application of the study. As this study aims at identifying environmental impacts up until the retailer for supply chain management, inclusion of the use and end-of-life phases would not be appropriate and lower the assessment efficiency. The study is not intended to be representative for pork production in general.

The study has taken into account the most up-to-date position papers on key methodological issues in the framework of the pilot test when applying PEF/OEF methods, i.e. for electricity modelling, functional unit definition for meat products, and the principles set by the Cattle Model Working Group, in particular for economic allocation.

\subsubsection{Functional unit}

Pork products are made in many different forms depending on market demand, consumer habits and dietary patterns: steaks, sausages, ribs, Orloff roast, etc. Considering that the purpose of the study is neither to evaluate the potential environmental impact of pork consumption nor of a specific pork form, but instead to look for optimisation in the supply chain, the analysis is limited to pure, fresh pork products.

The functional unit is $100 \mathrm{~g}$ fresh pig meat, including inedible parts such as bone, presented to consumers in retail packaging. Only meat with an average storage time is considered, excluding frozen pork. It is classified under Nomenclature statistique des Activités économiques dans la 
Communauté Européenne (NACE) code G47.2.2-Retail sale of meat and meat products in specialized stores (Humbert et al. 2015b; European Commission 2010) .

\subsubsection{System boundaries and cutoff criteria}

The system boundaries include all production chain steps until the purchase by consumers in the retail store (Fig. 2). The use and end-of-life phases are not included since pork has many use pathways depending on consumer preferences and it is not in line with the goal and scope of the study.

A distinction is made between the foreground system for which primary data is collected or specific calculation models are applied, and the background system for which life cycle inventory (LCI) data from databases is used (Tables 1, 2, 3, 4, 5, 6, 7, 8, 9; Ecoinvent v3.01 (Wernet et al. 2016); AgriFootprint v1.0, Blonk 2014; European Life Cycle Database v3.0; LCA Food Database, Nielsen et al. 2003; and OEF Sector Rules Retail, Humbert et al. 2015b).

The general rules followed are:

- The mass balance of the main product flow should fit to $100 \%$.

- Consumption goods are included for as far as data were readily available at plant level (e.g. utilities, diesel, feed ingredients, packaging, seeds, fertilizer, etc.).

- Major emissions are included (e.g. flue gases, agricultural emissions, hydrofluorocarbons (HFCs), unused gases)

- Waste treatment is included for solid wastes as well as wastewater.

- Capital goods (building infrastructure) and land use are included.
Table 1 Background datasets used for modelling feed ingredients production

Transported barley grain $\{$ GLO $\}$ (Colruytketen)

Oat grain, consumption mix, at feed compound plant/IE economic

Maize grain, organic $\{\mathrm{BE}\}$ Renaat Moors $\mid$ at feed compound Aveve (Colruytketen)

Wheat grain Renaat Moors, at feed compound plant Aveve

(Colruytketen)

Maize germ, dried, from wet milling (germ drying), at plant/FR Economic

Transported soybean $\{\mathrm{GLO}\}$ (Colruytketen)

Sunflower seed $\{\mathrm{GLO}\} \mid$ market for $\mid$ Alloc Def, $U$

Maize bran, from wet milling (drying), at plant/FR Economic

Sugar beet pulp, dried, consumption mix, at feed compound plant/NL Economic

Molasses, from sugar beet $\{\mathrm{GLO}\} \mid$ market for $\mid$ Alloc Def, $\mathrm{U}$

Crude palm oil, from crude palm oil production, at plant/ID

Economic

Crude maize germ oil, from wet milling (germ oil production, pressing), at plant/DE Economic

Monocalciumphosphate

Sodium chloride, powder $\{\mathrm{GLO}\} \mid$ market for $\mid$ Alloc Def, U

Wheat bran, consumption mix, at feed compound plant/NL

Economic

Rape meal $\{\mathrm{GLO}\} \mid$ market for $\mid$ Alloc Def, $\mathrm{U}$

Crude soybean oil, from crushing (pressing), at plant/NL Economic Rye grain $\{\mathrm{GLO}\} \mid$ market for $\mid$ Alloc Def, $U$

Triticale, consumption mix, at feed compound plant/NL Economic

Palm kernel meal $\{$ GLO $\} \mid$ market for $\mid$ Alloc Def, U

Calcium carbonate $>63 \mu \mathrm{m}$, production, at plant EU-27S

Distiller's dried grains with solubles $\{$ GLO $\} \mid$ market for $\mid$ Alloc Def, U

Soybean hulls, consumption mix, at feed compound plant/NL

Economic

Byproduct (fish oil)

Coconut oil, crude $\{\mathrm{GLO}\} \mid$ market for $\mid$ Alloc Def, $\mathrm{U}$

Magnesium oxide $\{$ GLO $\} \mid$ market for $\mid$ Alloc Def, $U$

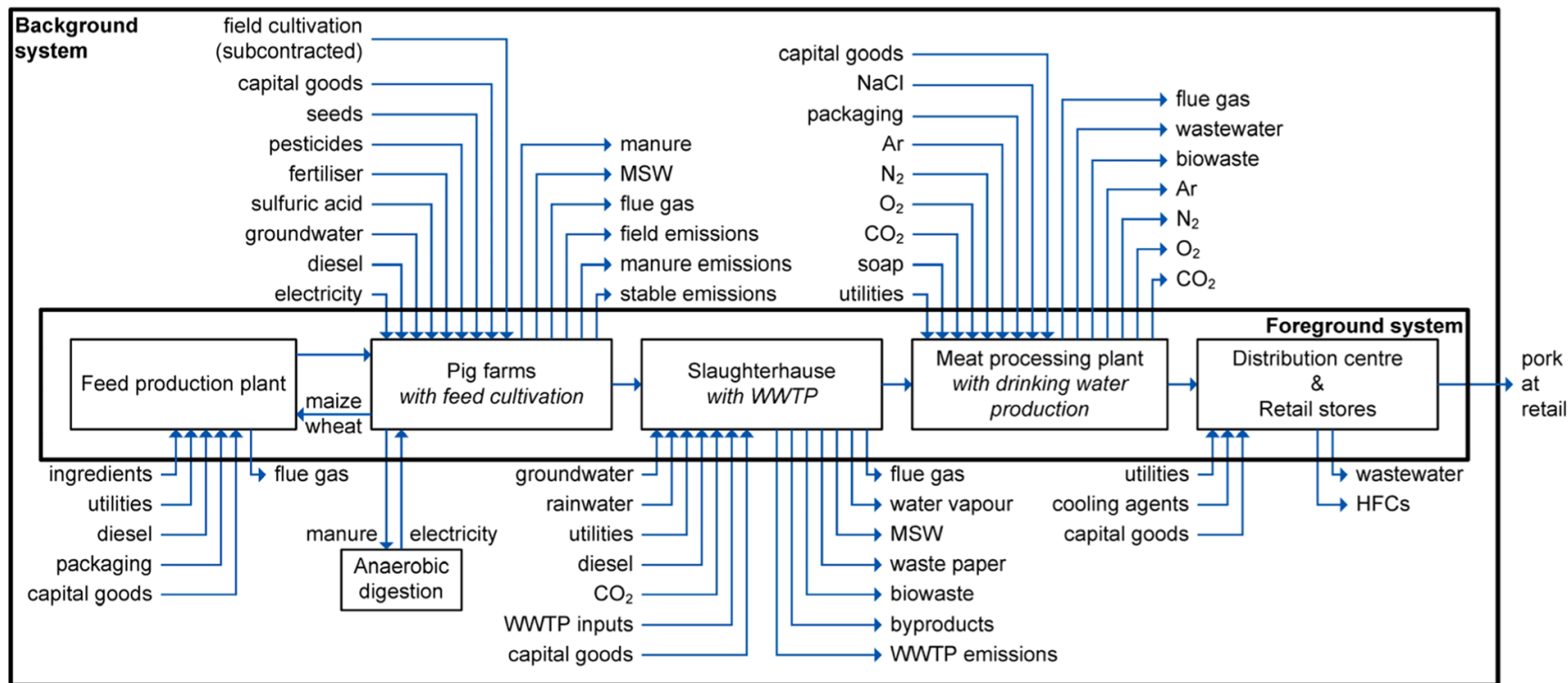

Fig. 2 System boundary diagram of the studied pork production chain (transport between foreground system units is also included; $W W T P$ waste water treatment plant, HFCs hydrofluorocarbons) 
Table 2 Background datasets used for modelling packed feed production

Transformation, from industrial area, built up

Transformation, to industrial area, built up

Occupation, industrial area, built up

Electricity, medium voltage $\{\mathrm{BE}\} \mid$ market for $\mid$ Alloc Def, $U$

Natural gas, burned in gas motor, for storage $\{N L\} \mid$ processing $\mid$ Alloc Def, U

Tap water, at user $\{\mathrm{CH}\} \mid$ market for $\mid$ Alloc Def, $U$

Diesel, burned in building machine $\{\mathrm{GLO}\} \mid$ market for $\mid$ Alloc Def, $\mathrm{U}$

Printed paper $\{\mathrm{GLO}\} \mid$ market for $\mid$ Alloc Def, $U$

Packaging film, low density polyethylene $\{\mathrm{GLO}\} \mid$ market for $\mid$ Alloc Def, U

Emissions to air

Carbon dioxide

Municipal solid waste (waste treatment) $\{\mathrm{BE}\} \mid$ treatment of municipal solid waste, incineration $\mid$ Alloc Def, $U$

Table 3 Background datasets used for modelling bulk feed production

Transformation, from industrial area, built up

Occupation, industrial area, built up

Transformation, to industrial area, built up

Electricity, medium voltage $\{\mathrm{BE}\} \mid$ market for $\mid$ Alloc Def, $U$

Natural gas, burned in gas motor, for storage $\{N L\} \mid$ processing $\mid$ Alloc Def, U

Tap water, at user $\{\mathrm{CH}\} \mid$ market for $\mid$ Alloc Def, $\mathrm{U}$

Diesel, burned in building machine $\{\mathrm{GLO}\} \mid$ market for $\mid$ Alloc Def, $\mathrm{U}$ Building, hall, steel construction $\{$ GLO $\} \mid$ market for $\mid$ Alloc Def, $U$

Table 4 Background datasets used for modelling farm A

Water, well, in ground, BE

Transformation, from agriculture

Transformation, to agriculture

Occupation, agriculture

Electricity, low voltage $\{\mathrm{BE}\} \mid$ market for $\mid$ Alloc Def, $\mathrm{U}$

Diesel, burned in building machine $\{$ GLO $\} \mid$ market for $\mid$ Alloc Def, $U$

Sulfuric acid $\{\mathrm{GLO}\} \mid$ market for $\mid$ Alloc Def, $U$

Transport, freight, lorry 16-32 metric ton, EURO4 \{RER $\} \mid$ transport,

freight, lorry 16-32 metric ton, EURO4 | Alloc Def, U

Building, hall, steel construction $\{$ GLO $\} \mid$ market for $\mid$ Alloc Def, U

Table 5 Background datasets used for modelling farm B

Water, well, in ground, BE

Transformation, from agriculture

Transformation, to agriculture

Occupation, agriculture

Diesel, burned in building machine $\{\mathrm{GLO}\} \mid$ market for $\mid$ Alloc Def, $U$

Sulfuric acid $\{\mathrm{GLO}\} \mid$ market for $\mid$ Alloc Def, $U$

Transport, freight, lorry 16-32 metric ton, EURO4 \{RER $\} \mid$ transport, freight, lorry 16-32 metric ton, EURO4 | Alloc Def, U

Electricity, low voltage $\{\mathrm{BE}\} \mid$ market for $\mid$ Alloc Def, $U$

Building, hall, steel construction $\{\mathrm{GLO}\} \mid$ market for $\mid$ Alloc Def, U
Table 6 Background datasets used for modelling the slaughterhouse

Water, well, in ground, BE

Water, rain

Transformation, from industrial area, built up

Occupation, industrial area, built up

Transformation, to industrial area, built up

Tap water, at user $\{$ Europe without Switzerland $\} \mid$ market for Alloc Def, U

Carbon dioxide, liquid $\{\mathrm{GLO}\} \mid$ market for $\mid$ Alloc Def, $\mathrm{U}$

Transport, freight, lorry 16-32 metric ton, EURO4 \{RER $\}$ | transport, freight, lorry 16-32 metric ton, EURO4 | Alloc Def, U

Building, hall, steel construction $\{\mathrm{GLO}\} \mid$ market for $\mid$ Alloc Def, U

Electricity, low voltage $\{\mathrm{BE}\} \mid$ market for $\mid$ Alloc Def, $\mathrm{U}$

Heat, central or small-scale, natural gas \{Europe without Switzerland\}| market for heat, central or small-scale, natural gas $\mid$ Alloc Def, U

Diesel, burned in building machine $\{\mathrm{GLO}\} \mid$ market for $\mid$ Alloc Def, $U$

Municipal solid waste (waste treatment) $\{\mathrm{BE}\} \mid$ treatment of municipal solid waste, incineration | Alloc Def, $U$

Waste paper, unsorted (waste treatment) \{Europe without Switzerland $\}$ | market for $\mid$ Alloc Def, $U$

Biowaste (waste treatment) $\{\mathrm{RoW}\} \mid$ treatment of manure and biowaste by anaerobic digestion $\mid$ Alloc Def, $U$

Comeco WWTP (Colruytketen) obv: Wastewater, average (waste treatment) $\{$ RoW $\} \mid$ treatment of, capacity 1.6E81/year | Alloc Def, U

Table 7 Background datasets used for modelling the meat processing plant

Transformation, from industrial area, built up

Transformation, to industrial area, built up

Occupation, industrial area, built up

Tap water, at user \{Europe without Switzerland $\} \mid$ market for Alloc Def, U

Soap $\{\mathrm{GLO}\} \mid$ market for $\mid$ Alloc Def, $U$

Carbon dioxide, liquid $\{$ GLO $\} \mid$ market for $\mid$ Alloc Def, $U$

Oxygen, liquid $\{\mathrm{GLO}\} \mid$ market for $\mid$ Alloc Def, $U$

Nitrogen, liquid $\{$ GLO $\} \mid$ market for $\mid$ Alloc Def, $U$

Argon, liquid $\{\mathrm{GLO}\} \mid$ market for $\mid$ Alloc Def, $\mathrm{U}$

Polypropylene, granulate $\{\mathrm{GLO}\} \mid$ market for $\mid$ Alloc Def, U

Polyethylene, low density, granulate $\{\mathrm{GLO}\} \mid$ market for $\mid$ Alloc Def, U

Corrugated board box $\{\mathrm{GLO}\} \mid$ market for corrugated board box $\mid$ Alloc Def, U

Paper, woodcontaining, lightweight coated $\{$ RER $\} \mid$ market for $\mid$ Alloc Def, U

Sawnwood, softwood, air dried, planed $\{$ RER $\} \mid$ planing, softwood, air dried $\mid$ Alloc Def, U

Soap $\{$ GLO $\} \mid$ market for $\mid$ Alloc Def, $U$

Sodium chloride, powder $\{$ GLO $\} \mid$ market for $\mid$ Alloc Def, $U$

Transport, freight, lorry 16-32 metric ton, EURO4 \{RER\}| transport, freight, lorry 16-32 metric ton, EURO4 | Alloc Def, U

Building, hall, steel construction $\{$ GLO $\} \mid$ market for $\mid$ Alloc Def, $U$

Electricity from wind power, $\mathrm{AC}$, production mix, at wind turbine, $<$ $1 \mathrm{kV}$ RER $\mathrm{S}$

Natural gas, burned in gas motor, for storage $\{\mathrm{GLO}\} \mid$ market for $\mid$ Alloc Def, U

Meat and bone meal (waste treatment) $\{\mathrm{GLO}\} \mid$ market for $\mid$ Alloc Def, U

Wastewater, average (waste treatment) $\{\mathrm{GLO}\} \mid$ market for $\mid$ Alloc Def, U 
Table 8 Background datasets used for modelling the distribution centre

Transformation, from industrial area, built up

Transformation, to industrial area, built up

Occupation, industrial area, built up

Transport, freight, lorry 16-32 metric ton, EURO4 \{RER $\} \mid$ transport, freight, lorry 16-32 metric ton, EURO4 | Alloc Def, U

Building, hall, steel construction $\{$ RoW $\} \mid$ building construction, hall, steel construction $\mid$ Alloc Def, $U$

Tap water, at user $\{$ Europe without Switzerland $\} \mid$ market for $\mid$ Alloc Def, U

Electricity, low voltage $\{\mathrm{BE}\} \mid$ market for $\mid$ Alloc Def, $\mathrm{U}$

Natural gas, burned in gas motor, for storage $\{\mathrm{NL}\} \mid$ processing $\mid$ Alloc Def, U

Ethane, pentafluoro-, HFC-125

Ethane, 1,1,1-trifluoro-, HFC-143a

Ethane, 1,1,1,2-tetrafluoro-, HFC-134a

Wastewater, average (waste treatment) $\{\mathrm{GLO}\} \mid$ market for $\mid$ Alloc Def, U

- Transport between plants is included.

- Commuting is excluded for comparability with other studies on the pig production chain, but included in the sensitivity analysis as it is a PEF requirement.

- Only readily available plant data are used and combined with literature models, no additional measurements are performed on-site.

Table 9 Background datasets used for modelling the retail stores

Transformation, from industrial area

Transformation, to industrial area

Occupation, industrial area

Transport, freight, lorry 7.5-16 metric ton, EURO4 \{RER $\} \mid$ transport, freight, lorry 7.5-16 metric ton, EURO4 | Alloc Def, U

Vlevico pig meat output (Colruytketen)

Colruyt Dassenveld pork (Colruytketen)

Building, hall, steel construction $\{$ RoW $\} \mid$ building construction, hall, steel construction | Alloc Def, U

Tap water, at user $\{$ Europe without Switzerland $\} \mid$ market for $\mid$ Alloc Def, U

Pine wood, timber, production mix, at saw mill, $40 \%$ water content DE S

Chromium steel pipe $\{\mathrm{GLO}\} \mid$ market for $\mid$ Alloc Def, $\mathrm{U}$

Computer, desktop, without screen $\{\mathrm{GLO}\} \mid$ market for $\mid$ Alloc Def, U

Metal working, average for steel product manufacturing $\{$ RER $\} \mid$ processing | Alloc Def, U

Electricity, low voltage $\{\mathrm{BE}\} \mid$ market for $\mid$ Alloc Def, $U$

Ethane, pentafluoro-, HFC-125

Ethane, 1,1,1-trifluoro-, HFC-143a

Ethane, 1,1,1,2-tetrafluoro-, HFC-134a

Wastewater, average (waste treatment) $\{\mathrm{GLO}\} \mid$ market for $\mid$ Alloc Def, U

\subsubsection{Assumptions}

The following assumptions were made in general or for each of the chain actors as not all required modelling data were readily available.

General:

- Electricity use is assumed to be from the Belgian power grid (average mix) unless stated otherwise.

Feed production:

- Feed packaging materials are assumed to be incinerated after use.

- Utility use for packed feeds is assumed to be the same as for bulk feeds.

- Ninety-four percent of feed ingredients (by mass) were assigned specific background datasets in order to calculate their impact. The remaining $6 \%$ was assumed to have the same average impact so that the known feed ingredient impact could be upscaled to $100 \%$ as an estimation of the total impact.

Animal husbandry:

- Derivative maize products such as maize bran are assumed to come from the feed market.

- Sows are assumed to occupy their place in the stables for 1 year.

- Specific for farm A:

- The on-site produced maize and wheat are assumed to be directly used for pig feed for the farm.

- Because the wheat and maize production and consumption numbers are close to each other, it is assumed that all the maize and wheat is from own production (with the mass and impact rescaled to the exact number).

- Specific for farm B:

- The maize consumed at farm B is assumed to have a similar impact to that produced at farm A.

- Greenhouse gas emissions:

- Half of the nitrogen taken up by the plant is assumed to stay on the field as corn stover.

- The average weight of a fattening pig assumed to be $70 \mathrm{~kg}$, the average weight of piglets $7 \mathrm{~kg}$ and the average weight of sows $200 \mathrm{~kg}$ 
- Phosphate runoff to surface water:

- The factor $\mathrm{P}_{2} \mathrm{O}_{5 \mathrm{sl}}$ is assumed to be $90.3 \mathrm{~kg} \mathrm{ha}^{-1}$.

- Wheat production:

- The grain/straw mass ratio is assumed to be similar to that used in the Agri-Footprint database (Blonk 2014), namely 1.82 .

- No subcontracting is assumed.

- Electricity from biogas:

- $\quad$ Expert judgement (Velghe F., senior project engineer at OWS, personal communication) is used to quantify the biogas potential and electricity generation: $40 \mathrm{~m}^{3}$ biogas/ ton pig manure and $2 \mathrm{kWh}$ electricity $/ \mathrm{m}^{3}$ biogas.

Meat processing:

- For packaging, the PEF guidelines for meat are used: $25 \mathrm{~g}$ plastic packaging and $2.5 \mathrm{~g}$ paper for the label per kilogram fresh meat (Technical Secretariat for the Fresh Meat Pilot 2014), assuming that the plastic is $50 \% \mathrm{PP}$ and $50 \% \mathrm{PE}$.

Distribution centre:

- Half of the meat is assumed to pass the distribution centre on its way to retail while the other half is transported directly to retail.

Transport:

- The transport distance from Halle (where both the meat processing and distribution centre are located) to the retail stores and back is assumed to be $160 \mathrm{~km}$ as most of the Colruyt retail stores are found within this range.

- Transport in between foreground units is modelled following the OEF Sector Rules Retail (Humbert et al. 2015b): it is assumed to be performed by lorry without taking into account any cooling needs.

Commuting:

- Commuting is assumed to be negligible for the farms as the farmers live on-site.

- Employees relying on a mixture of bicycle, foot, bus, tram, or train are assumed to have a relatively small impact compared to cars (based on Pickery 2005; BorkenKleefeld et al. 2010).
2.3.4 Impact assessment method, normalization and weighting

The environmental impacts are calculated at the midpoint level using the environmental impact categories, characterization factors and indicators recommended in the PEF Guidance. The calculations are performed using the international reference life cycle data system (ILCD) 2011 Midpoint + V1.06 method as implemented in SimaPro 8.0.5.13.

As far as normalization is concerned, according to the most up-to-date position papers by the European Commission (Galatola 2015), normalized and equally weighted PEF results present some inconsistencies stemming from errors at various levels of the assessment. For this reason, normalization has not been carried out in this study.

\subsubsection{Treatment of multifunctionality}

The environmental impacts associated with the feed production process are assigned by subdivision of the production plant. The farms produce both meat pigs and piglets between which the impact is allocated by mass. The slaughterhouse produces pork as well as several by-products (e.g. intestines). The impact is allocated by economic value between the meat products and the by-products at a 90:10 ratio (Coenegrachts J., director at Covalis, personal communication), in line with the Cattle Model. The impacts associated with the meat processing are allocated by mass.

The end-of-life formula recommended in the PEF/OEF guidelines for dealing with multifunctionality in recycling situations has not been applied as recycling or energy recuperation benefits were not considered in the applied waste treatment models. This aspect does not affect the compliance with the PEF methodology but has been taken into account for calculating the data quality rating.

\subsection{Process descriptions}

\subsubsection{Feed production}

Primary data describing the processing of different ingredients into feeds was collected at a large feed production site (AVEVE Veevoeding in Merksem, Belgium; total yearly production $>800,000 \mathrm{t}$ ) through a short meeting with the R\&D and quality assurance manager of the organisation who provided utility and diesel use as well as feed composition data. The gathered data represent the year average consumption in 2013.

The feed production plant is subdivided in four main units: reception and storage, cattle feed production, specialty feed 
Table 10 Data quality assessment (quality ratings can range from excellent (1) to very poor (5))

\begin{tabular}{|c|c|c|c|}
\hline Data quality criterium & & $\begin{array}{l}\text { Quality } \\
\text { rating }\end{array}$ & Rationale \\
\hline $\begin{array}{l}\text { Technological } \\
\text { representativeness }\end{array}$ & $(\mathrm{TeR})$ & 2 & $\begin{array}{l}\text { All technologies included in the foreground system of the study were effectively applied at the } \\
\text { analysed unit operations. Background data may deviate somewhat from reality as these are often } \\
\text { made up from average production methods. Background data was selected in order to match } \\
\text { reality as closely as possible }\end{array}$ \\
\hline $\begin{array}{l}\text { Geographical } \\
\text { representativeness }\end{array}$ & (GR) & 2 & $\begin{array}{l}\text { Most data was gathered at the specific processing plants in Belgium. Some background data is } \\
\text { however more generic and not specific for the considered locations (e.g. using global averages). } \\
\text { Background data was selected in order to match reality as closely as possible }\end{array}$ \\
\hline Time-related representativeness & (TiR) & 5 & $\begin{array}{l}\text { All gathered foreground data originates from the year 2013. Background datasets and models used } \\
\text { are however often more than } 5 \text { years older than the foreground data. Background data was } \\
\text { selected in order to match reality as closely as possible }\end{array}$ \\
\hline Completeness & (C) & 2 & $\begin{array}{l}\text { Completeness is assumed to be good as all but one of the PEF impact categories were considered } \\
\text { and all relevant in- and outputs of the foreground processes have been taken into account (only } \\
\text { part of the capital goods and commuting were not included and } 6 \% \text { of the feed ingredients (by } \\
\text { mass) were assumed to have similar impacts to the other } 94 \% \text { ). Omitting the commuting data has } \\
\text { an impact of max. } 10 \% \text { and an average of } 2 \% \text { of the total impacts. For the toxicity related impact } \\
\text { categories, detailed data was however limited }\end{array}$ \\
\hline Parameter uncertainty & $(\mathrm{P})$ & 2 & $\begin{array}{l}\text { The resource use and emissions data is judged to be of low uncertainty as most data originates from } \\
\text { calibrated measurements (e.g. energy use and legally regulated emissions) or recent, published } \\
\text { calculation models. Standard deviations from these measurements are unknown but assumed to } \\
\text { be limited }\end{array}$ \\
\hline $\begin{array}{l}\text { Methodological } \\
\text { appropriateness and } \\
\text { consistency }\end{array}$ & $(\mathrm{M})$ & 3 & $\begin{array}{l}\text { Multifunctionality was dealt with appropriately. No cutoff was applied. Fossil and biogenic carbon } \\
\text { emissions and removals were modelled separately (biogenic carbon emissions are not taken into } \\
\text { account in the used ILCD method). GHG emissions from direct land use change were taken into } \\
\text { account. No credits were considered for carbon storage or delayed emissions. No emissions } \\
\text { off-setting were included. Most of the capital goods were included. All major processes directly } \\
\text { linked to the product supply chain were included within the system boundaries. No 50/50 } \\
\text { end-of-life modelling was included }\end{array}$ \\
\hline
\end{tabular}

production, and monogastric feed production. The reception and storage units are shared among the other three units. Data was available per unit and since the cattle feed and specialty

Table 11 Average data quality ratings for the datasets with the largest impacts, together responsible for at least $70 \%$ of the total impact in the effect category

\begin{tabular}{ll}
\hline Effect category & Data quality rating \\
\hline Climate change & 2.54 \\
Ozone depletion & 2.67 \\
Human toxicity, cancer effects & 2.44 \\
Human toxicity, non-cancer effects & 2.00 \\
Particulate matter & 2.33 \\
Ionizing radiation HH & 2.67 \\
Photochemical ozone formation & 2.54 \\
Acidification & 2.17 \\
Terrestrial eutrophication & 1.78 \\
Freshwater eutrophication & 2.57 \\
Freshwater ecotoxicity & 2.51 \\
Land use & 2.37 \\
Water resource depletion & 2.62 \\
Mineral, fossil and ren. resource depletion & 2.67 \\
\hline
\end{tabular}

feed production units are separated entirely from the monogastric feed production and are not linked to its impact, both are excluded from this study.

Utility consumption was considered equal per mass unit for all products within one production unit. The impact of feed packaging was allocated only to those feeds that are sold in bags. No additional utilities, e.g. electricity for the packing process, were allocated to the packaged feeds due to lack of detailed data.

The following feeds are used by the farmers in this study and were analysed in detail, taking into account their specific ingredients and inclusion or omission of packaging. For piglets: Biggispeen Balans meel, Biggispeen Balans kruimelig meel, Biggistart Balans meel and Biggistart Balans kruimelig meel. For breeding sows: Optifok II korrel. For meat pigs: Optipro korrel, Optivo Grow korrel - omega 3, Premium Pro korrel, Premium Finish korrel, Premium Grow korrel, Premium Grow korrel - omega 3, Premium Pro korrel, Premium Pro korrel - omega 3 and Premium Transit korrel. For nonbreeding sows: Fertiflush korrel, Fertimax korrel, Lactomax korrel, Easylac korrel and Fertimax korrel. The feeds are composed out of about 50 different ingredients such as barley, wheat, maize, oats, soy, palm oil, maize oil, salt, etc. $94 \%$ of the feed mass fraction was 
modelled matching the ingredients, the remaining $6 \%$ was assumed to have a similar specific impact due to lack of matching datasets.

\subsubsection{Animal husbandry}

Two Belgian pig farms (A and B) were included in the study. Data was gathered from the detailed bookkeeping and environmental reports of each during a short, on-site interview with the farmers.

Farm A grows pigs and piglets as well as sugar beet, Cichorium, maize and wheat. The latter two crops are transported to the feed production plant and assumed to be incorporated into the pig feed used at the farm. The produced amount is similar to the consumed amount. As such, it is assumed that all consumed maize and wheat are produced on-site. Derivative products such as maize bran, germ, etc. come from the feed market. The power needs of farm A are also partially met on-site by photovoltaic electricity production. On-site transport by tractor and stable heating are powered by fuel oil. Water is extracted directly from the ground.

The maize grain production at farm A is modelled using data provided by the farmer combined with readily available literature data. The farm applies $\mathrm{K}_{2} \mathrm{O}$ fertilizer, other nutrients are delivered by manure from the pigs. Manure $\mathrm{N}$ and $\mathrm{P}_{2} \mathrm{O}_{5}$ concentrations are based on literature (Coppens, 2009). Other inputs are ground water, fuel oil and maize seeds. A default pesticide mix is used. The harvesting is subcontracted and therefore modelled using Ecoinvent v3.01 (Wernet et al. 2016). Emissions such as $\mathrm{NH}_{3}, \mathrm{NO}, \mathrm{N}_{2} \mathrm{O}, \mathrm{CH}_{4}, \mathrm{CO}_{2}, \mathrm{NO}_{3}$ and $\mathrm{PO}_{4}$ are calculated using emission models and literature data (Bengoa et al. 2014; De Neve et al. 2006; Nyamangara et al. 2003; LNE 2011).

The wheat production at farm A is also modelled. The grain/straw ratio is based on that used in the Agri-Footprint database (Blonk 2014). Mineral fertilizer is added (as a generic market mix) as well as sow manure. Other inputs in the process are ground water, fuel oil and wheat seeds. A default pesticide mix is used. No subcontracting is taken into account. Emissions are calculated similarly to the production of maize grain, but with adjusted addition of $\mathrm{N}\left(79 \mathrm{~kg} \mathrm{~N} \mathrm{ha}^{-1}\right.$ in manure and $55 \mathrm{~kg} \mathrm{~N}^{-1}$ in mineral fertilizer) and $\mathrm{P}_{2} \mathrm{O}_{5}$ $\left(58 \mathrm{~kg} \mathrm{P}_{2} \mathrm{O}_{5}\right.$ ha $\left.^{-1}\right)$ based on information provided by the farmer. For calculation of nitrate emissions, wheat root depth and nitrogen uptake were taken into account. The impact related to sugar beet and Cichorium production is excluded from the study as this is not linked to the pig production.

Farm B produces grown pigs, maize and potatoes at three different sites. The maize is used for pig feed production. The maize production impact is approximated by that of farm A because detailed data regarding the agricultural activities on farm B were unavailable due to subcontracting. Electricity on this farm originates entirely from the grid. Fuel oil is used for stable heating and powering tractors. Water is extracted from the ground. Most of the manure is processed in an off-site anaerobic digestion plant with electricity production, the amount of which is determined by expert judgement (Velghe F., senior project engineer at OWS, personal communication). The anaerobically produced electricity substitutes part of the grid power consumption of farm B.

The following direct gaseous emissions from the stables and manure were calculated using emission models. Ammonia emissions were determined taking into account the difference between regular and low ammonia emission stables (Van Gansbeke 2012), the latter achieves lower emissions by e.g. limiting the contact time between manure and atmospheric air. $\mathrm{N}_{2} \mathrm{O}$, methane and $\mathrm{CO}_{2}$ emissions were calculated based on a review study (Philippe and Nicks 2014). $\mathrm{NO}_{\mathrm{X}}$ emission was taken into account by combining the $\mathrm{N}$ content of the liquid manure with a fixed emission factor (Bengoa et al. 2014).

The impacts caused by on-site manure use for fertilization were taken into account, while those caused by traded manure were not since the latter are outside of the scope of this study.

\subsubsection{Slaughterhouse}

The slaughterhouse in this study is a modern, large-scale plant slaughtering around 1,000,000 pigs per year (Comeco in Hoogstraten, Belgium). Data was collected at the level of the slaughtering plant during an on-site meeting with the plant director.

Upon arrival at the slaughterhouse, pigs spend a short period in stables where they are calmed down with the aid of warm water sprays. Their manure is collected. Subsequently, the animals are sedated by immersion in a $\mathrm{CO}_{2}$ bath after which they are hung and stabbed for blood extraction. After heat treatment, dehairing with collection of the hair, and skin flaming, the animals are partitioned into carcasses and byproducts are removed. Finally, the carcasses are split up into smaller parts before export to different customers.

Whereas the slaughterhouse processes pigs from a large number of farmers, in this study, we simulate that the input stream of pigs is made up entirely out of pigs produced at farms $\mathrm{A}$ and $\mathrm{B}$ since we do not want to mix the final result with generic datasets in the foreground system. The mass of pigs coming from both farms has been upscaled based on the ratio of their actual production (36\% from farm A and $64 \%$ from farm B) to match the total pig mass processed in the slaughterhouse.

Waste processing scenarios are modelled using Ecoinvent v3.01 (Wernet et al. 2016). Utilities of the on-site wastewater treatment plant are taken into account. The subsequently emitted water meets environmental regulations for discharge in surface waters. Sludge processing is taken into account and emissions of $\mathrm{CO}_{2}, \mathrm{CO}, \mathrm{NO}_{\mathrm{x}}, \mathrm{SO}_{2}$ and particulate matter (PM) 
from steam boilers and flame ovens are included based on actual measurements.

\subsubsection{Meat processing}

The slaughtered pigs are processed into different pork products in the meat processing plant (Fine Food Meat in Halle, Belgium). Data is collected at the level of the plant combined with data from the organisational level through an on-site meeting with one of the plant managers.

After reception and internal distribution of the pig parts, they are cut and stored. Next, the pork is either exported or processed further on-site in the portioning and packing, or charcuterie and slicing departments. The exported products are transported in cooled trailers or carts, either to the distribution centre (Dassenveld, which is also located in Halle) or directly to retail stores. Cooling of the trucks has not been accounted for.

The wastewater treatment is a combination of different installations, purifying part of the water to drinking water quality for internal reuse and the remaining wastewater to the levels needed for evacuation into surface waters. The impact associated with the construction and maintenance of each of the installations is modelled using generic data from wastewater treatment plants.

\subsubsection{Distribution centre}

Half of the meat is estimated to pass through the distribution centre while the other half is transported directly to retail. The impact of the distribution centre (Dassenveld in Halle, Belgium) is difficult to allocate due to a large and diverse throughput of products, some of which undergo processing steps such as cutting or packaging. For this reason the impact of Dassenveld is approximated by the OEF Sector Rules Retail for cooled storage (Humbert et al. 2015b) and allocated based on economics. The model includes many inputs, including refrigerant emissions.

\subsubsection{Retail}

The impact of the retail stores (Colruyt Laagste Prijzen) is also approximated by the OEF sector rules retail (Humbert et al. 2015b). The model includes many inputs, including refrigerant emissions. Due to lack of details, the chairs included in the model are not taken into account. Since packaging materials are already included at the meat processing plant, these are not added again at this step.

\subsubsection{Transportation}

Transport is included for the feed ingredients with the largest mass fractions. These are soy, barley, maize and wheat. From the feed production on-site, the transportation between the considered foreground system unit operations is included up until the retail stores. These transportation steps are performed by lorry.

\subsection{Data quality}

The quality of the data used for this study is determined following PEF guidelines (Manfredi et al. 2012; European Commission 2013c). The assessment is discussed briefly for each of the data quality criteria in Table 10 .

The overall data quality rating (DQR) is calculated as follows:

$\mathrm{DQR}=\frac{\mathrm{TeR}+\mathrm{GR}+\mathrm{TiR}+\mathrm{C}+\mathrm{P}}{5}=\frac{2+2+5+2+2}{5}=2.6$

With TeR = technological representativeness; GR = geographical representativeness; $\mathrm{TiR}=$ time-related representativeness; $\mathrm{C}=$ completeness; and $\mathrm{P}=$ parameter uncertainty. The achieved DQR is considered to indicate data of good quality.

Besides the determination of the overall data quality, the data quality per impact category was also determined using the same calculation method as above for those process datasets that contribute the most and together are responsible for at least $70 \%$ of the impact in that category and by expert judgement for those processes that combined contribute up to at least $90 \%$ of the category impact. The calculated average data quality results per impact category (together responsible for $70 \%$ of the impact) are shown in Table 11, resulting in very good to good quality ratings in all impact categories. The other considered data (responsible for the 70-90\% interval contributions) were determined to be of good quality by expert judgement. More than $90 \%$ of the impact in every category is thus caused by datasets of good or very good quality.

\section{Results and discussion}

\subsection{Life cycle impact assessment results and hotspot analysis}

The total environmental impacts associated with the pork production chain are listed in Table 12. The environmental hotspots throughout the production chain are shown in Fig. 3 and discussed below. Both only for those results which are not considered highly uncertain in the uncertainty analysis.

Overall, feed production and farming are responsible for more than half of the total impact in each of the selected impact categories, mostly followed by meat processing. The slaughterhouse is less important while wholesale and retail show negligible impact contributions.

Water resource depletion is mostly caused by electricity consumption throughout the foreground processes $(48 \%)$ 
and feed production, especially barley grain (18\%) and soybean $(7 \%)$. The inclusion of infrastructure (building construction) is responsible for $6 \%$ of the total impact. Other contributions such as the extraction of groundwater at the farms are less important individually ( $<5 \%$ of the total) but do add up to $21 \%$.

Freshwater eutrophication is mostly caused by emissions during farming ( $76 \%$; both feed ingredient production and pig farming) and by the processing of waste meat products originating from the meat processing plant (16\%; the Ecoinvent v3.01 (Wernet et al. 2016) scenario assumes mainly incineration).

Particulate matter is mostly caused by ammonia emissions at farm level and by the tractors used in the farms. Feed ingredient production and transport are responsible for most of the remaining impact.

Ozone depletion is especially linked to electricity and diesel consumption throughout the chain. The diesel related emissions are caused by both heating and transport use.

Acidification is mainly caused by ammonia emissions (and to a lesser extent, sulphur and nitrogen oxides) at farm level $(56 \%)$. Most of the remaining impact is caused by the feed ingredient production processes ( $>35 \%$ ).

Terrestrial eutrophication is mostly caused on-site at the farms $(58 \%)$ by ammonia emissions during animal breeding. The remaining impact is almost entirely caused by the feed ingredients due to, e.g. the application of manure for fertilizing wheat, maize, barley, soybean, etc.

Mineral, fossil and renewable resource depletion impacts are largely caused by the building infrastructure used in the foreground processes $(74 \%)$ and more precisely, the zinc that is used in this background dataset. The impact is concentrated

Table 12 Pork production total environmental footprint (per $100 \mathrm{~g}$ pork at retail)

\begin{tabular}{|c|c|c|}
\hline Impact category & Quantity & Unit \\
\hline Climate change & 4.6E-01 & $\mathrm{kg} \mathrm{CO}_{2}$ eq \\
\hline Ozone depletion & 1.7E-08 & kg CFC-11 eq \\
\hline Human toxicity, cancer effects & $1.2 \mathrm{E}-08$ & $\mathrm{CTU}_{\mathrm{h}}$ \\
\hline Human toxicity, non-cancer effects & $6.9 \mathrm{E}-07$ & $\mathrm{CTU}_{\mathrm{h}}$ \\
\hline Particulate matter & $3.1 \mathrm{E}-04$ & $\mathrm{~kg} \mathrm{PM}_{2.5} \mathrm{eq}$ \\
\hline Ionizing radiation $\mathrm{HH}$ & $5.5 \mathrm{E}-02$ & $\mathrm{kBq} \mathrm{U}^{235}$ eq \\
\hline Photochemical ozone formation & $1.3 \mathrm{E}-03$ & kg NMVOC ec \\
\hline Acidification & $9.8 \mathrm{E}-03$ & molc $\mathrm{H}^{+}$eq \\
\hline Terrestrial eutrophication & 4.2E-02 & molc $\mathrm{N}$ eq \\
\hline Freshwater eutrophication & $9.2 \mathrm{E}-05$ & $\mathrm{~kg} P$ eq \\
\hline Freshwater ecotoxicity & $2.6 \mathrm{E}+00$ & $\mathrm{CTU}_{\mathrm{e}}$ \\
\hline Land use & $8.0 \mathrm{E}+00$ & $\mathrm{~kg} \mathrm{C}$ deficit \\
\hline Water resource depletion & $1.4 \mathrm{E}-01$ & $\mathrm{~m}^{3}$ water eq \\
\hline Mineral, fossil and ren. Resource depletion & 4.6E-05 & $\mathrm{kg} \mathrm{Sb}$ eq \\
\hline
\end{tabular}

at the farming stage due to the used stables which are relatively large for their pig throughput compared to the other foreground processes.

Climate change impact contributions are discussed in detail in the following paragraphs and shown in Fig. 4 which presents the growth of the carbon footprint throughout the studied pork production chain. The transport steps from the meat processing plant to the distribution centre and further to the retailer are negligible in the overall carbon footprint and are therefore omitted from the figure.

At the meat processing plant, the main meat input causes the highest share of the impact (94\%) whereas packaging, transport, natural gas, wastewater treatment, cleaning products and other utilities represent a smaller, combined impact of $0.03 \mathrm{~kg} \mathrm{CO}_{2}$-eq.

The slaughtering shows a similar image: $97 \%$ of its impact is caused by the supply of meat whereas the remainder is mostly caused by utilities (transport from the farms, (grey) electricity, the natural gas burned for flaming, etc.). Other inputs such as gases, diesel, water and waste treatment are negligible. Bracquené et al. (2011) reports a higher addition by the slaughterhouse, but takes into account waste processing of the meat waste, whereas in this case study all these waste products are valorised.

The pork impact originates for $31 \%$ from farm A and $61 \%$ from farm B. This is not due to large differences in farming practises, but rather because of the larger scale of farm B and the proportionate allocation of mass input of the two suppliers (36\% from A and $64 \%$ from B). This actually means that the impact per mass of pig produced is quite comparable for both farms.

The pigs delivered by farm $\mathrm{A}$ have an impact of $3.1 \mathrm{~kg} \mathrm{CO}$-eq per kilogram pig whereas the pigs delivered by farm $\mathrm{B}$ have a carbon footprint of $3.4 \mathrm{~kg} \mathrm{CO}_{2}$-eq per kilogram pig. Interestingly, this difference is mainly caused by difference in feed supply of the two farms. The feed conversion ratio of both farms is in the same order of magnitude (2.7-2.8 kg feed per kilogram pig), but the impact of the premium feed series is generally higher than the Opti feed series, mainly due to higher amounts of palm products, and to a lesser extent soybean products, in the premium series.

Direct emissions of dinitrogen monoxide and methane are very important (31-32\%) causes of greenhouse gas emissions for both animal husbandries. This is in line with what is found in other studies (e.g. Bracquené et al. (2011) reports around $30 \%$ of the total carbon footprint). These emissions are indeed inherent to the breeding of pigs and can hardly be mitigated. Other aspects that are contributing less are the heating systems of the stables $(2-3 \%)$ which are for most farms based on fuel oil, and transport of feed ingredients $(1-3 \%)$. The latter is a bit higher for the farm that is situated further from 
Fig. 3 Environmental footprint distribution throughout the supply chain (omitting highly uncertain results)

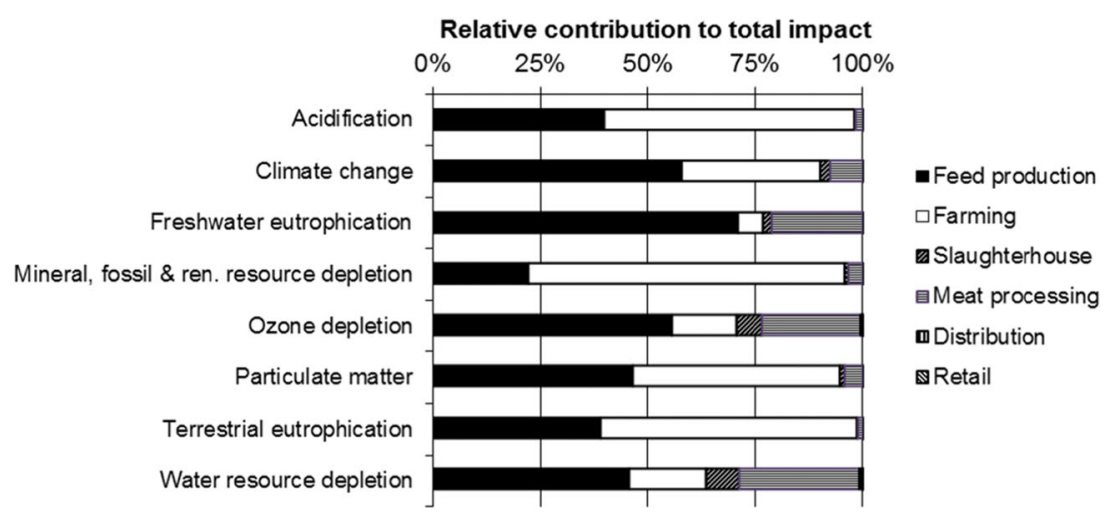

the feed production plant in Merksem. Electricity use on the farms generally has a low impact on climate change, which is enhanced by the fact that both farmers are involved in renewable energy projects (photovoltaics and biogas production).

As expected, the feed production has an important share in the total burden of the pork production chain. In this production chain, $0.24 \mathrm{~kg} \mathrm{CO}_{2}$-eq. or $52 \%$ of the total carbon footprint, originates from feed production. Only $2.5 \%$ of this impact is caused by the production process in Merksem, whereas $97.5 \%$ originates from production and transport of feed ingredients. Grains or grainrelated products (e.g. bran) mainly from Belgium/Europe have the largest share in this impact $(48 \%)$, followed by soybean $(29 \%)$ and palm oil $(17 \%)$. Other ingredients such as sunflower seeds, beet pulp, etc. have a smaller share.

\subsection{Sensitivity}

Sensitivity analyses have been carried out to test the extent to which the main assumptions adopted for modelling the supply chain affect the overall results. In particular, the sensitivity of the following aspects has been considered: inclusion of commuting, different origin of the maize, ammonia emission model, ranges for sow ammonia and greenhouse gas emissions. The significance of the resulting differences is assessed statistically using Welch's $t$ test at the $95 \%$ certainty level. The standard deviation required for this test was determined by Monte Carlo simulation with 1000 runs.

Commuting is not included in the main results due to lack of detailed data. The potential impact of this decision is quantified by combining site data with averages from literature. Table 13 summarizes the used employee data. As listed in Table 14, most of the employees use their car for commuting.

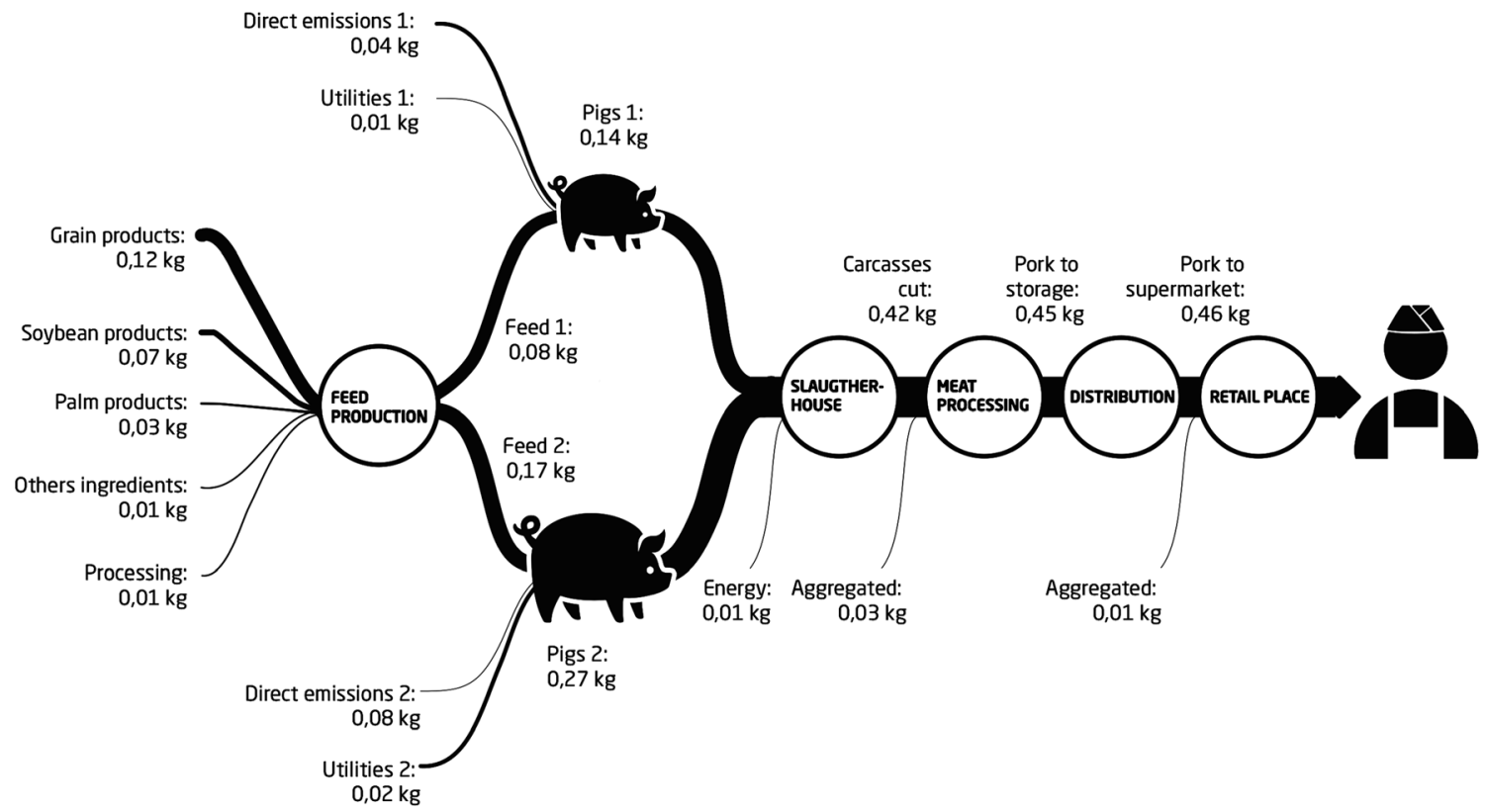

Fig. 4 Carbon footprint distribution throughout the supply chain $\left(\mathrm{kg} \mathrm{CO}_{2}\right.$-eq. $(100 \mathrm{~g})^{-1}$ pork at retail) 
Table 13 Summary of employee commuting data

\begin{tabular}{llcl}
\hline Site & Number of employees & Allocation to pork chain $(\%)$ & Rationale for allocating \\
\hline Feed production & 260 & 1 & Allocation by mass of total production that is destined for farms A and B \\
Farms & $1-2$ & 100 & Commuting assumed to be negligible \\
Slaughterhouse & 80 & 2 & Allocation by mass of pork originating from farms A and B \\
Meat processing & 850 & 3 & Allocation by mass of pork originating from farms A and B \\
Distribution and retail & 26,150 & 0.1 & Estimate based on turnover \\
\hline
\end{tabular}

The others rely on a mixture of bicycle, foot, bus, tram or train. This mix is not modelled for the sake of simplicity, as it is assumed to have a small impact compared to the transport by car. As can be seen in Fig. 5, the effect of adding commuting to the total impact is relatively small. It significantly increases the impact in terms of freshwater eutrophication, ozone depletion, particulate matter and water resource depletion.

The maize grains used in the feeds are assumed to originate from local production at farm A. In order to assess the sensitivity of this modelling decision, the total impact of the pork chain using this local maize grain is compared to a model in which a general, global average production dataset is used to which transport from France to the feed production compound is added (Huysveld S., Ghent University, personal communication). The total impact of the pork at supermarket is significantly better when using local maize in terms of freshwater eutrophication, ozone depletion, particulate matter and water resource depletion (Fig. 6).

The ammonia emission model could be replaced by that of Bengoa et al. (2014) which do not differentiate between low ammonia emission and regular stables instead of the one by Van Gansbeke (2012) which does differentiate between both types. The impact of using this alternative model is shown in Fig. 7. The sensitivity for the ammonia emission model is limited to three impact categories: acidification, particulate matter and terrestrial eutrophication. The higher values for the model by Bengoa et al. (2014) are not surprising since the alternative model does not differentiate between low ammonia emission and regular stables.

Ammonia emissions in animal husbandry are calculated using the average from the range of emission factors provided in literature for sows in both low ammonia emission and regular stables. In order to assess the sensitivity of the pork chain model to this decision, the model is ran again with both the

Table 14 Commuting data (based on Pickery 2005)

\begin{tabular}{lcl}
\hline Transport mode & Amount & unit \\
\hline Employees by car & 70 & $\%$ \\
Employees by bicycle, foot, bus, tram or train & 30 & $\%$ \\
Average single distance & 19 & $\mathrm{~km}$ \\
Commuting frequency & 254 & days year $^{-1}$ \\
\hline
\end{tabular}

lowest and highest values from the ranges. The sensitivity of the model to changing the sows' ammonia emission factors to the maximum or minimum values of the range is minimal and only in terms of acidification, particulate matter and terrestrial eutrophication (Fig. 8).

Greenhouse gas emissions in animal husbandry are calculated using the average from the range of emission factors provided in literature for sows in both low ammonia emission and regular stables. In order to assess the sensitivity of the constructed model to this decision, it is ran again with both the lowest and highest values from the ranges. Variation of the exact choice of greenhouse gas emission factors for the sows did not lead to significant differences to the overall environmental impact results in any of the impact categories.

\subsection{Uncertainty}

The uncertainty of the midpoint results was determined statistically by performing a Monte Carlo uncertainty simulation (10,000 runs, $95 \%$ confidence interval) and determining the coefficient of variation $(\mathrm{CV})$ of the overall results in every impact category (Fig. 9).

Water resource depletion shows the least uncertainty (CV of $13 \%$ ) followed by freshwater eutrophication, particulate matter, ozone depletion, acidification, terrestrial eutrophication, mineral, fossil and renewable resource depletion and climate change. The other impact categories all result in CV's above $100 \%$, reaching up to $4874 \%$ for human toxicity and non-cancer effects. The latter results thus have very low certainty and would likely lead to incorrect conclusions. They are therefore omitted from the study results.

In addition to the high CV found in the Monte Carlo simulation, land use is also considered uncertain due to the applied calculation method. Although it is the current ILCD (JRC-IES 2011) recommended method (Milà I Canals et al. 2007), it should be used carefully as it is based upon very generic data, its scope is limited to soil organic matter (excluding e.g. biodiversity) and it is classed as 'level III: recommended, but to be applied with caution’ (JRC-IES 2012).

The different toxicity categories are also highly uncertain, especially in agriculture. This uncertainty is caused by e.g. the modelling of the heavy metals spread with the manure for which 
Fig. 5 Sensitivity of the model to including commuting to the foreground processes (insignificant differences not shown)

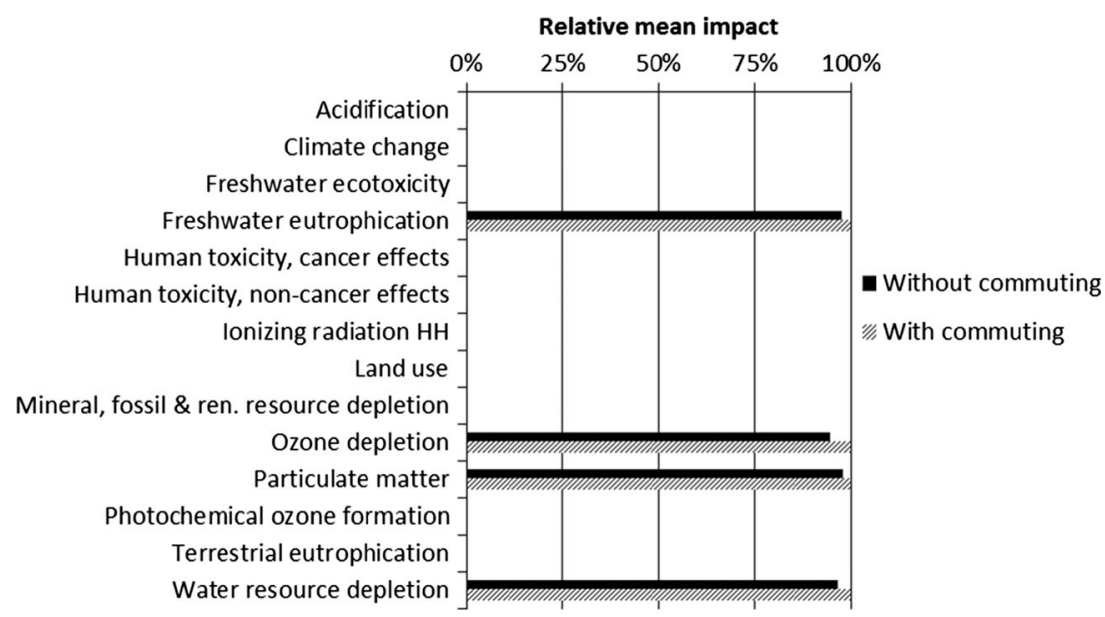

an Ecoinvent v3.01 (Wernet et al. 2016) dataset detailing organic maize farming was used, as well as the emissions from pesticide use, agricultural vehicle tyre wear and waste water treatment for which insufficient details were available in order to adequately determine their total contribution to the overall results.

\subsection{Chain-OEF in practice}

Pragmatic data collection throughout the supply chain plays an important role in the chain-OEF approach. Foreground data collection is evaluated as follows for each of the plants:

- Feed production facility. Utility usage data was relatively easily available at the level of the different production units. Data for feed compositions was also available but required more work due to the large diversity of different feed products with all their specific ingredients. Feed does, however, represent an important impact in the meat supply chain. It is therefore important to gather detailed compositions at the level of specific brands rather than making one average animal feed mix. Including specific brand names allows farmers to link their feed choice directly to their environmental impact.

- Animal husbandries. Whereas data collection for agricultural processes is generally seen as difficult, farmers in Western Europe generally have very detailed bookkeeping and low overhead. Therefore, it is surprisingly easy to gather the required inventory data. However, data on direct elementary flows such as air emissions is more difficult to gather and requires expert knowledge and emission models to calculate.

- Slaughterhouse and meat processing. Data was relatively easily available at plant level. The slaughterhouse is a very linear process and therefore quite straightforward, whereas the meat processing site produces a multitude of outputs. In this study, we have chosen for the group of fresh pig meat, whereas many preparations are made as well, using a large range of utilities such as onion, pepper, port, mayonnaise, etc. This list is very elaborated and therefore time consuming. In that sense it is important to choose a functional unit that fits the goal and scope, which can be the optimisation of the meat supply chain or communication
Fig. 6 Sensitivity of the model to using global average maize production instead of locally produced maize (insignificant differences not shown)

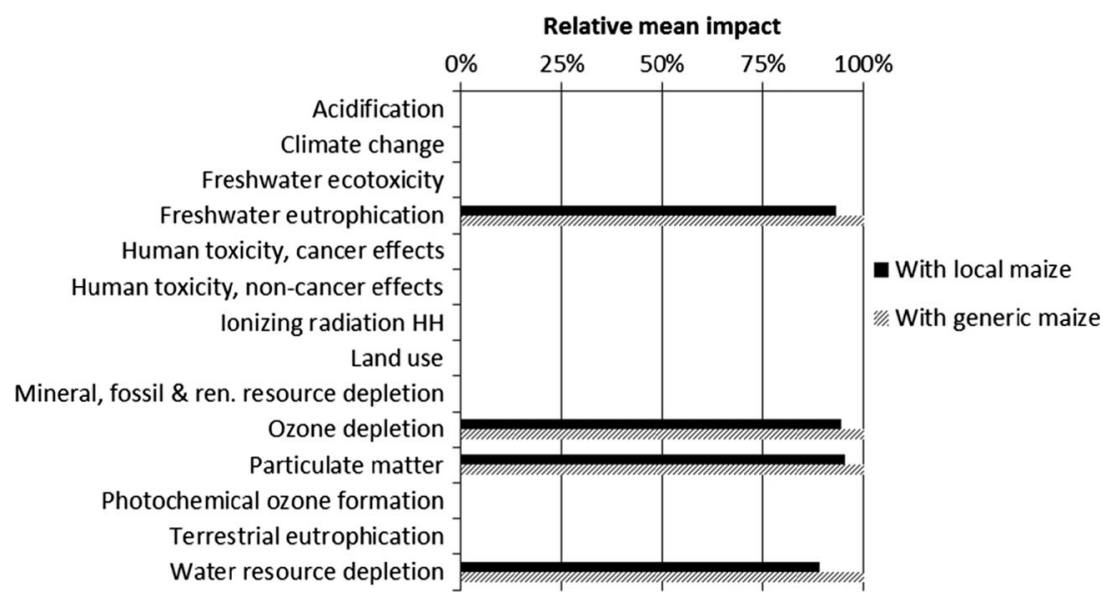


Fig. 7 Sensitivity of the model to using the ammonia emission model presented by Bengoa et al. (2014) instead of the model by Van Gansbeke (2012) (insignificant differences not shown)

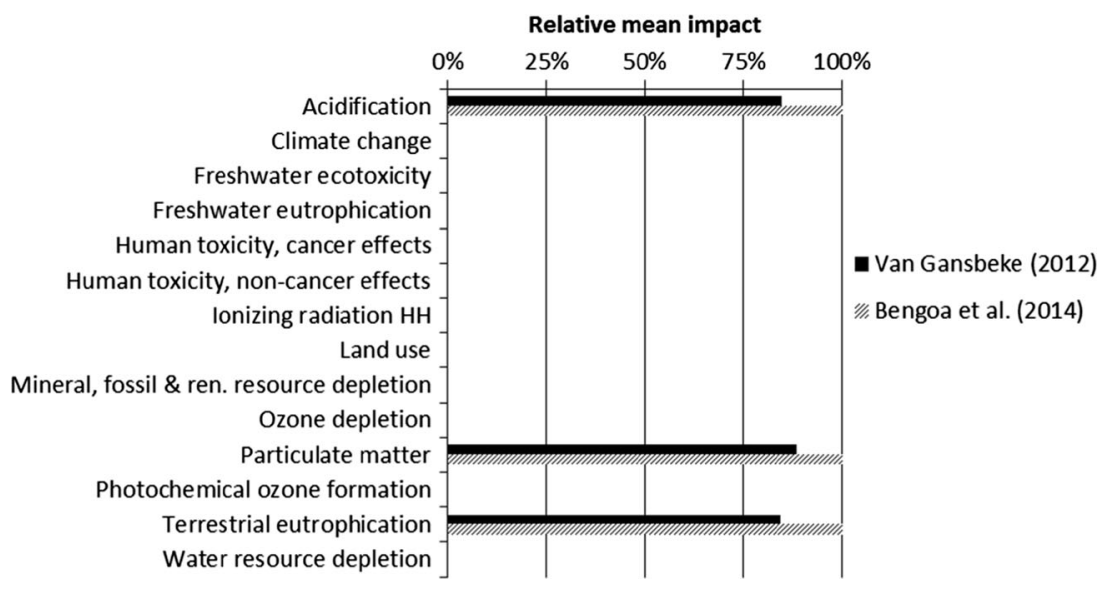

to consumers. In the latter case, it might be advisable to differentiate between specific preparations.

- Distribution centre and retail stores. Data gathering and allocation are rather complicated. In general, the impression is that the larger the company, the more complex the organogram, and consequently, the more distributed the data.

In contrast to the general feeling that it is difficult to involve farmers and small or medium-sized enterprises (SMEs) in LCAs because of data availability and effort, we experienced that data is more easily available for these actors and only requires an interview of approximately $2 \mathrm{~h}$ followed by a short analysis of the bookkeeping. The latter is also easily done if data can be aggregated at plant or business unit level on a yearly basis. This is in contrast to large industries in which data is very dispersed and a longer collection phase is required with more interviews and more difficult allocation keys. However, large organizations can often put more effort into sustainability issues and are often the driving force behind LCAs.
The basic availability of data in supply chains of developed countries is not an issue, at least when all involved actors are located in the same country. The main bottlenecks arise elsewhere:

- Bookkeeping data are not directly usable as life cycle inventories. The data needs to be processed, transformed or completed with literature data or calculation models. Currently, this requires the involvement of a sector specialist and an LCA expert, increasing the cost of the study. Therefore, means should be sought to facilitate this step.

- Data is confidential between supply chain actors and often none of the results or only the impact assessment results can be communicated. This can be done by an independent third party, but it would be beneficial to have a data management platform in which supply chain actors can manage their own data, let it be reviewed and let the LCA results be communicated to clients and suppliers, partners, governments, etc.

- Most importantly, the supply chain actors such as SMEs and farmers have relatively fast access to data but the main
Fig. 8 Sensitivity of the model to the ammonia emission factor range for sows, relative to average factor results (insignificant differences between min. and max. results not shown)

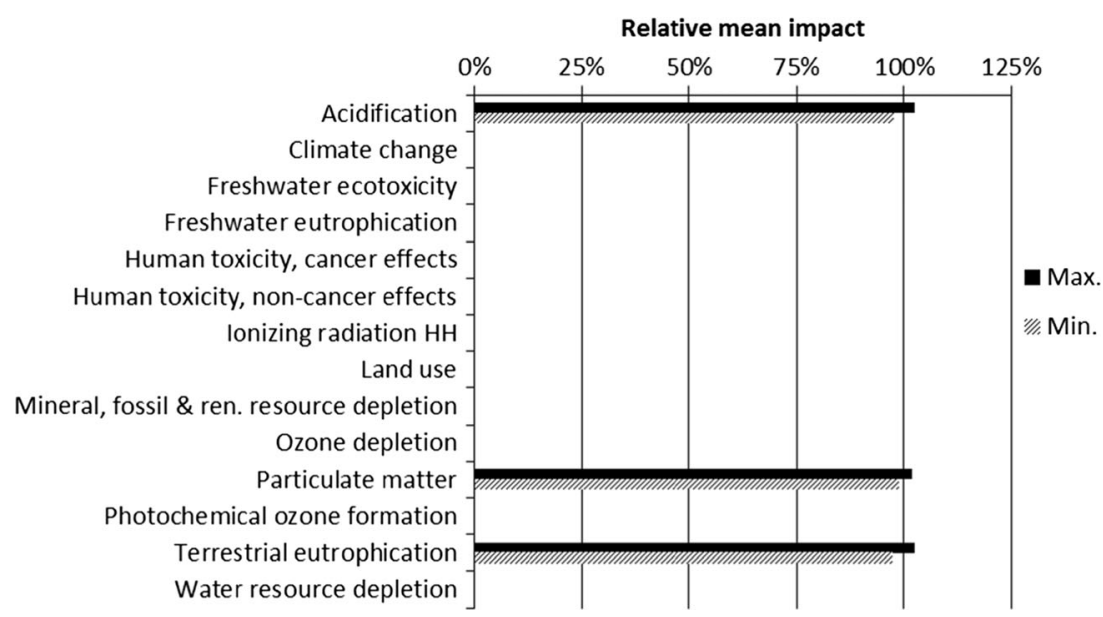




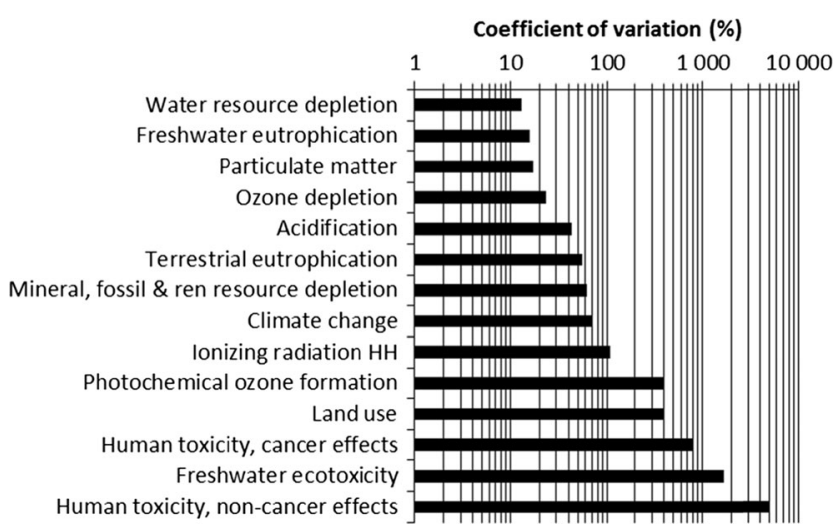

Fig. 9 Uncertainty analysis: coefficients of variation for every midpoint impact category (based on a Monte Carlo simulation of 10,000 runs with $95 \%$ confidence interval)

bottleneck is to convince them to spend effort on an LCA study or at least to spend effort collecting and forwarding the required data to LCA practitioners.

For this purpose, we have brought the supply chain actors together. The general feeling is that performing an LCA is useful and delivers interesting insights, especially on hotspots in the supply chain. On the other hand, there is also a feeling that an LCA stops too early, namely when the LCA result becomes available. The insights from the study should be used to actually induce positive change. Figure 10 shows different drivers to make changes to supply chains; one pull and three push strategies are identified:

- Pull: eco-branding. Consumers become more conscious about environmental issues and believe that they can play an important role in a transition to a greener society through sustainable consumption. Consumers can therefore induce a positive dynamic in value chains, but whereas they want to make sustainable choices, they do not always know exactly how to do this due to the unavailability of simple and reliable information. Clearly labelling environmentally friendly products can increase their consumption (Vlaeminck et al. 2014).

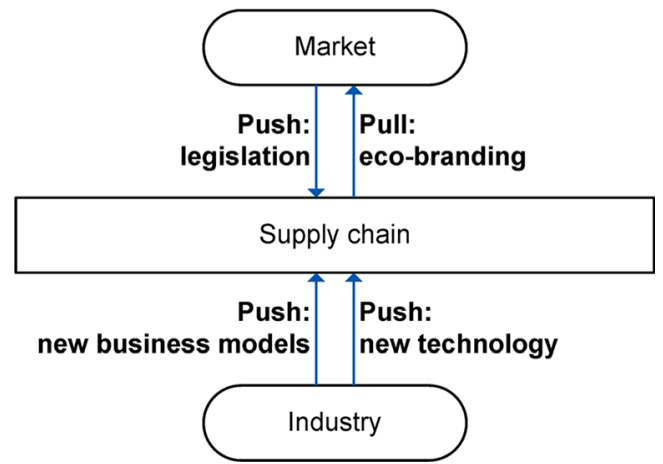

Fig. 10 Strategies to find additional added value from LCA studies which can be used to convince supply chain actors to join
- Push: legislation. The European PEF/OEF offers a harmonised life cycle assessment methodology that can be used to underpin both recommended and mandatory European and regional policies.

- Push: technology. The consumption of energy and other resources often represents a major part of the product cost. Managing these resources in a more efficient, more sustainable manner by using innovative technologies will not only lead to cost savings across value chains, enhancing the economic benefit and thus the competitiveness of companies, but, more importantly, will also have an ecological benefit, decreasing the overconsumption of natural resources.

- Push: new business models. Innovations can not only be identified for a single production stage, but they can be established by introducing industrial ecology/symbiosis principles within value chains and within industrial clusters. Furthermore, in order to take up a leading role, businesses may require environmental practices from their suppliers that are more demanding than those required by legislation.

Although some efforts have already been made, we find further research on these aspects essential for the large-scale implementation of the environmental footprint system. Based on current knowledge of LCA experts, it remains difficult to introduce these drivers for change within an LCA study. Efforts related to LCA should thus go further than solely harmonisation and methodological discussions. Instead, we should take the opportunity of a harmonised approach to focus on more multi-disciplinary aspects, such as communication of LCA/PEF/OEF results, use of LCA in policy, the combination of LCA and engineering and best practices of technologies, and the systematic identification of new business models such as industrial symbiosis within and outside of supply chains.

\section{Conclusions}

\subsection{Impact of the analysed pork production chain}

As expected based on literature study (Blonk 2014; ERM/ Ghent University 2011; Rougoor et al. 2015), feed production and farming are responsible for an important share of the total burden of the pork production chain. The conclusions are discussed below, but only for those impact categories with the least uncertainty.

Water resource depletion is mostly caused by feed ingredient production (especially barley, soybean and sunflower seeds), electricity consumption and infrastructure of the foreground processes. Freshwater eutrophication is mostly caused by emissions during farming (especially feed ingredient production) and by the processing of waste meat products originating from the meat processing plant. Almost half of the particulate matter impact is caused by ammonia emissions at farm level and by the tractors 
used in the farms. Feed ingredient production and the associated transport are responsible for most of the remaining impact. Ozone depletion is especially linked to electricity and diesel consumption throughout the chain. Acidification is mainly caused by ammonia emissions (and to a lesser extent sulphur and nitrogen oxides) at farm level. Most of the remaining impact is caused by the feed ingredient production processes. Terrestrial eutrophication is mostly caused on-site at the farms by ammonia emissions during animal breeding, the remaining impact is almost entirely caused by the feed ingredients. The impact in terms of mineral, fossil and renewable resource depletion is largely caused by the building infrastructure used in the foreground processes and more precisely the zinc that is used in this background dataset.

Fifty-two percent of the total carbon footprint originates from feed production. Grains, or grain-related products (e.g. bran), mainly from Belgium/Europe have the largest share in this impact, followed by soybean and palm oil. Other ingredients such as sunflower seeds, beet pulp, etc. have a smaller share. Both pig farmers have similar climate impacts despite the choice for different feeds. This is explained by the lower emissions originating from farm $\mathrm{B}$ being combined with the use of feeds which have a higher impact than those used by farm A. Since feed conversion ratios are similar it can be assumed that the pig farming process could be improved further by combining the low emission stables of farm B with the more environment-friendly feeds selected at farm A (more of the Opti feeds instead of the Premium feeds). The production chain steps after the farms only add small impacts to the total carbon footprint (a few percentages per step). This was somehow anticipated, but the effect is larger than expected, most probably due to very efficient production plants and other environment-friendly initiatives.

\subsection{Applying chain-OEF}

Chain-OEF combines the PEF and OEF guidelines to come to an efficient supply chain assessment. Several elements of these guidelines lead to interesting results: not only the total impacts and hotspots are identified using standardized methods but uncertainties are also assessed, sensitivities are checked and improvement potentials are evaluated, all leading to valuable insights and more correct interpretation of the results. The most important point of discussion that arose during the drafting and reviewing of the study was that of the data quality rating. As this is largely based on subjective quantification of qualitative parameters, it is difficult to come to mutual agreement. Evaluating the different criteria qualitatively surely adds value for the reader by summarizing the most important data quality aspects, but we expect the quantified rating to have little real value due to its subjective nature. Another issue is that of the high uncertainty associated with the results in terms of the toxicity impact categories, land use and resource depletion. This issue is also discussed by the Technical Advisory Board of the European
Commission and is considered a problem in many $\mathrm{PEF} / \mathrm{OEF}$ pilots. Including quantified results from these impact categories can easily lead to misunderstandings, especially among non-specialists. Taking into account renewable electricity use proven by guarantees of origin was another point of discussion. The PEF and OEF guidelines allow this if a statement by the utility is added to the study as proof. In practice, the required document was not always easily obtainable and its environmental value is questionable, considering the fact that e.g. renewable electricity generation in Iceland can be taken into account in Belgium, despite the lack of electrical links between both, or that intermittent renewable generation without storage can fully replace the average grid mix. Finally, the current rules allow a subjective choice of allocation methods. For comparability between studies, it might be better to define specific allocation methods for every sector or activity type.

Applying the chain-OEF approach in this study has shown that a product environmental footprint can indeed be calculated successfully based on primary process and overhead data throughout the supply chain. Primary data was sometimes more easily available than expected in this pork supply chain, especially for SMEs or farmers. The clue for large-scale implementation of PEF/OEF studies in supply chains would thus be:

- The installation of a data management platform in which LCA results can be exchanged with respect for confidentiality and

- The link of LCA studies to drivers towards positive change in supply chains.

In this case study, all actors agreed to join since they are already frontrunners. The animal feed production plant is very efficient and almost negligible in the production chain. Both farmers take initiatives to lower emissions, to increase the food conversion ratio, to increase the number of pigs per sow and to produce electricity from renewable resources. The slaughterhouse and meat processing facility are very efficient with state-of-the-art equipment and waste treatment facilities. The already existing knowledge of the chain and motivation throughout the chain have thus already paid off, resulting in a lower footprint compared to market averages. On the other hand, currently there is a limitation in available tools to use the available LCA results towards further optimization. Therefore we suggest to perform research beyond harmonisation and methodological aspects and also perform multi-disciplinary research that allows push or pull measures from market and industry, in which the PEF/OEF system can be the central harmonised methodology towards improvement of environmental performance.

Acknowledgements The authors would like to thank AVEVE Veevoeding, Comeco, both anonymous farmers and Fine Food Meat for their cooperation. 


\section{Compliance with ethical standards}

Funding This study was funded by Colruyt Group which owns the meat processing site (Fine Food Meat), the distribution centre (Dassenveld) and the retail stores (Colruyt Laagste Prijzen) analysed in this study. The other chain actors (AVEVE Veevoeding, Comeco and the farmers) are part of the pork supply chain of Colruyt Group.

Open Access This article is distributed under the terms of the Creative Commons Attribution 4.0 International License (http:// creativecommons.org/licenses/by/4.0/), which permits unrestricted use, distribution, and reproduction in any medium, provided you give appropriate credit to the original author(s) and the source, provide a link to the Creative Commons license, and indicate if changes were made.

\section{References}

Agri-Footprint (2014) LCA database

Bengoa X et al. (2014) World Food LCA Database. Methodological guidelines for the life cycle inventory of agricultural products. Version 2

Blonk (2014) Agri-footprint - description of data. V 1.0

Borken-Kleefeld J, Berntsen T, Fuglestvedt J (2010) Specific climate impact of passenger and freight transport. Environ Sci Technol 44(15):5700-5706

Bracquené E, Fernagut M, Goossens K, Jacobsen R, Vandermeulen V, Gellynck X, De Smet S, Boeckx P, Van Huylenbroeck Gx (2011) Toepassen van de Carbon Footprint methodologie op Vlaamse veehouderijproducten. ERM, Ghent University. Vlaamse overheid, Departement Landbouw en Visserij, afdeling Monitoring en Studie

Carlsson-Kanyama A (1998) Climate change and dietary choices-how can emissions of greenhouse gases from food consumption be reduced? Food Policy 23(3-4):277-293

Coppens G (2009) Bodemkundige Dienst van België. De mestwegwijzer - Overzicht van 15 jaar mestanalyse door de Bodemkundige Dienst van België

Dalgaard R, Halberg N, Hermansen JE (2007) Danish pork productionan environmental assessment. DJF animal science no. 82

De Neve $S$ et al (2006) Soil nutrient status of organic farms in Flanders: an overview and a comparison with the conventional situation. Biol Agric Hortic 24:217-235

De Schryver A, Chappert B, Humbert S (2012) Organization environmental footprint study for Colruyt Group. Confidential report

Djekic I, Radović Č, Lukić M, Lilić S, Stanišić N (2015) Environmental life-cycle assessment in production of pork products. MESO, vol. XVII, no. 5

European Commission (2010) List of NACE codes

European Commission (2013a) Building the single market for green products facilitating better information on the environmental performance of products and organisations. Communication from the Commission to the European Parliament and the Council. COM/ 2013/0196 final

European Commission (2013b) Commission recommendation of 9 April 2013 on the use of common methods to measure and communicate the life cycle environmental performance of products and organisations. Annex III: Organisation Environmental Footprint (OEF) Guide. 2013/179/EU. Official Journal of the European Union, L 124, Volume 56, May 4th, 2013

European Commission (2013c) Commission recommendation of 9 April 2013 on the use of common methods to measure and communicate the life cycle environmental performance of products and organisations. 2013/179/EU. Official Journal of the European Union, L 124, Volume 56, May 4th, 2013
Finkbeiner M (2014) Product environmental footprint — breakthrough or breakdown for policy implementation of life cycle assessment? Int J Life Cycle Assess 19:266-271

Finnveden G, Moberg A (2005) Environmental systems analysis toolsan overview. J Clean Prod 13:1165-1173

Galatola M. (2015) Disclaimer normalised and weighted results. Final, April 2015. EU environmental footprint pilot phase - support and documents-documents of common interest. Available at https://webgate.ec.europa.eu/fpfis/wikis/display /EUENVFP/Documents+of+common+interest

Galatola M, Pant R (2014) Reply to the editorial "product environmental footprint - breakthrough or breakdown for policy implementation of life cycle assessment?" written by prof. Finkbeiner. Int J Life Cycle Assess 19:1356-1360

Gerber PJ, Steinfeld H, Henderson B, Mottet A, Opio C, Dijkman J, Falcucci A, Tempio G (2013) Tackling climate change through livestock - A global assessment of emissions and mitigation opportunities. Food and Agriculture Organization of the United Nations (FAO), Rome

Guinée JB, Heijungs R, Huppes G, Zamagni A, Masoni P, Buonamici R, Ekvall T, Rydberg T (2011) Life cycle assessment: past, present and future. Environ Sci Technol 45:90-96

Humbert S (2015a) OEF retail screening report in the context of the EU Organization Environmental Footprint Sector Rules (OEFSR) Pilots

Humbert S, Dubois C, Guignard C, Pedrazzini S, Adams A (2015b) Organisation Environmental Footprint Sector Rules (OEFSR): retail. Version of July 9, 2015

Ilbery B, Maye D (2005) Food supply chains and sustainability: evidence from specialist food producers in the Scottish/English borders. Land Use Policy 22(4):331-344

JRC-IES (2011) ILCD handbook. Recommendations for Life Cycle Impact Assessment in the European context-based on existing environmental impact assessment models and factors. EUR $24571 \mathrm{EN}$ - 2011

JRC-IES (2012) Characterisation factors of the ILCD recommended life cycle impact assessment methods - database and supporting information. EUR $25167 \mathrm{EN}$ - 2012

Lehmann A, Bach V, Finkbeiner M (2015) Product environmental footprint in policy and market decisions: applicability and impact assessment. Integr Environ Assess Manage 11(3):417-424

LNE (2011) Erosie in Vlaanderen

Manfredi S, Allacker K, Chomkhamsri K, Pelletier N, de Souza DM (2012) Product Environmental Footprint (PEF) guide. Deliverable 2 and $4 \mathrm{~A}$ of the administrative arrangement between DG environment and the joint research centre no N 070307/2009/552517, including Amendment No 1 from December 2010

Milà I Canals L, Bauer C, Depestele J, Dubreuil A, Freiermuth Knuchel R, Gaillard G, Michelsen O, Müller-Wenk R, Rydgren B (2007) Key elements in a framework for land use impact assessment within LCA. Int J Life Cycle Assess 12:5-15

Nielsen PH, Nielsen AM, Weidema BP, Dalgaard R, Halberg N (2003) LCA food database

Nyamangara J, Piha MI, Giller KE (2003) Effect of combined cattle manure and mineral nitrogen maize $\mathrm{N}$ uptake and grain yield. Afr Crop Sci J 11(4):289-300

Pedrazzini S, Humbert S, Dubois C, Adams A, Grossmith A, Léglise P, Vermeiren F, Van Hemelryck S, Schreiber H, Poivet R, Wildenberg M, Comploi K, Zamagni A, Masoni P, Aubry E (2014) The EU Organisation environmental footprint applied to the retail sector. Proceedings of the 9th international conference on life cycle assessment in the agri-food sector

Philippe FX, Nicks B (2014) Review on greenhouse gas emissions from pig houses: production of carbon dioxide, methane and nitrous oxide by animals and manure. Agric Ecosyst Environ 199:10-25 
Pickery J (2005) Pendelen in Vlaanderen. Een analyse van het woonwerkverkeer op basis van SEE2001. OVERWERK Tijdschrift van het Steunpunt WAV 4:76-81

Quantis (2015) Organization environmental footprint study for Colruyt Group

Rougoor C, Elferink E, Lap T, Balkema A (2015) LCA of Dutch porkassessment of three pork production systems in the Netherlands. GLAMUR

Technical secretariat for the fresh meat pilot (2014) PEF pilot meat; Overview of existing PCRs, draft scope, representative product. Draft version 1

TNS Opinion \& Social (2014) Attitudes of European citizens towards the environment. Special Eurobarometer 416 "Attitudes of European citizens towards the environment". doi: 10.2779/25662
Van Gansbeke S (2012) Ammoniakemissie-arme stalsystemen voor varkens en pluimvee

Vlaeminck P, Jiang T, Vranken L (2014) Food labeling and eco-friendly consumption: experimental evidence from a Belgian supermarket. Ecol Econ 108:180-190

VLAM (2014) Belgian meat-facts \& figures 2014

Wernet G., Bauer C., Steubing B., Reinhard J., Moreno-Ruiz E., Weidema B. (2016) The ecoinvent database version 3 (part I): overview and methodology. The International Journal of Life Cycle Assessment, [online] 21(9):1218-1230. Available at: http://link. springer.com/10.1007/s11367-016-1087-8

Winkler T, Schopf K, Aschemann R, Miniwarter W (2016) From farm to fork - a life cycle assessment of fresh Austrian pork. J Clean Prod 116:80-89 